\title{
Effect of Dynamic Geometry Software on 3-Dimensional Geometric Shape Drawing Skills
}

\author{
İbrahim Kepceoğlu \\ Correspondence: İbrahim Kepceoğlu, Kastamonu University, Faculty of Education, Department of Science and \\ Mathematics Education, Kastamonu, Turkey.
}

Received: April 10, 2018

doi:10.11114/jets.v6i10.3197
Accepted: August 14, $2018 \quad$ Online Published: August 17, 2018

URL: https://doi.org/10.11114/jets.v6i10.3197

\begin{abstract}
In order to be able to draw accurately and to interpret the drawings properly, the skills of the students' drawing skills and therefore spatial visualization and spatial orientation must be developed. The studies in the literature are mostly concerned with examining the spatial skills of students with various models or investigating the effects of different methods and techniques on the spatial skills of students. For this reason, the effect of dynamic geometry software on the three-dimensional shapes of elementary school mathematics teacher candidates has been examined in this study. The mixed method research paradigm is chosen as the methodology of this study. This research involves two parts: the first is, under quantitative paradigm, the true experiment and the second is, under qualitative paradigm, case study. In the true experimental design. 30 pre-service elementary mathematic teachers are divided randomly into two groups as control and experiment group. 15 pre-service teachers in the experiment group participated to the Cabri 3D Plus workshop for 3 weeks. According to the results of the research, it is revealed that the candidates of the Cabri 3D program have an effect on the drawing of three dimensional geometric shapes.
\end{abstract}

Keywords: dynamic geometry; drawing skill; pre-service mathematics teachers

\section{Introduction}

Geometry is important for every student because it provides a natural environment for the development of students' ability to think and demonstrate (NCTM, 2000). Experience gained in the classroom environment for geometric concepts improves the spatial ability of students (Hoover, 1996). Spatial thinking is the ability to visualize objects and the current situation in their minds. Drawing explanatory forms when solving problems, turning tables and graphics when verbal problems are given, and understanding the relation between geometric forms show that this skill has improved (Turgut, 2010). Therefore, the use of abstract geometric concepts, the spatial ability of the spatial situations in mind, forms the basis of spatial thinking. The development of spatial capability will also allow for an easier understanding of the mathematical and geometric issues. Nevertheless, the issue of how best to develop spatial capability continues to be the focus of research in different areas.

Many researchers have stated that spatial ability has an important role in understanding geometry (Unal, Jakubowski \& Corey, 2009). The American National Council of Teachers of Mathematics (NCTM) (2000) emphasized the importance of geometry as "a natural field for the development of reasoning and proofing skills of geometry students." It also focuses on spatial skills in geometry learning and teaching (NCTM, 2000), expressing "the main reason for the development of the spatial skills of learners is to interpret objects with spatial meanings and to understand the world of geometry of students." Individuals with high spatial skills can more easily grasp geometric shapes and resolve relationships between shapes (Turgut, 2010).

One of the hardest parts of geometry lessons is drawing. It is both time consuming and difficult for both the two-dimensional and three-dimensional forms to be interpreted by students and by teachers. This is especially true in the drawing of three-dimensional figures. In order to make the drawings of spatial objects correctly, it is necessary to know deeply the properties of the objects (Kösa, 2010). At the same time, the correct drawings are very important for students to perceive geometric structures correctly (Accascina \& Rogara, 2006). In addition, both the drawing and the evaluation are more likely to encounter difficulties when it is necessary to switch from two dimensions to three dimensions and from three dimensions to three dimensions. Students who have met three-dimensional objects from the first stage of primary education make their own drawings of the shapes given in later periods. When the mathematics 
curricula in Turkey are examined, it is seen that they are mostly focused on two-dimensional plane geometry. Keeping in mind that all human beings are living in three-dimensional space, three-dimensional thinking should be more important, but in curricula this part is weak. When the subject of space geometry is processed when secondary education is passed, the emphasize on this subject remains still weak (Baki, 2008).

It is also very difficult for students to understand space and dimension concepts. Students especially have difficulty in displaying three-dimensional shapes in two dimensions (Ben-Chaim, Lappn \& Houang, 1988). It is not easy to draw the shapes given on a piece of paper. It requires a skill to accurately draw the two-dimensional appearance of objects by taking into consideration the viewing angle and geometric shape's characteristics. Correct drawings are very important in order to make accurate comments about these objects. There are also a few studies on understanding the concept of dimension (Skordoulis, Vitsas, Dafermos \& Koleza, 2009; Vitsas \& Koleza, 2000; Ural, 2011).

Research shows that spatial thinking is more concerned with geometry than mathematics (Battista, 1990, Grande, 1990, Karaman, 2000). Moreover, it is stated that using spatial skills is related to two-dimensional geometry rather than three-dimensional geometry (Baki, Kösa \& Karakuş., 2008). In order to be able to draw accurately and to interpret the drawings properly, the skills of the students' drawing skills and therefore spatial visualization and spatial orientation must be developed. The studies on spatial visualization and spatial orientation are frequently seen in the literature (Uygan, 2011; Baki \& Güven, 2007; Kösa, 2011; Karaman, 2000). These studies are mostly concerned with examining the spatial skills of students with various models or investigating the effects of different methods and techniques on the spatial skills of students. In these studies, there is not much emphasis on drawing skills. Also, there are no studies in the field about drawing two-dimensional and three-dimensional shapes only. For this reason, the effect of dynamic geometry software on the three-dimensional shapes of elementary school mathematics teacher candidates has been examined in this study.

\section{Methodology}

The mixed method research paradigm is chosen as the methodology of this study. This research involves two parts: the first is, under quantitative paradigm, the true experiment and the second is, under qualitative paradigm, case study. In the true experimental design (Cohen, Manion \& Morrison, 2000), 30 pre-service elementary mathematic teachers are divided randomly into two groups as control and experiment group. 15 pre-service teachers in the experiment group participated to the Cabri 3D Plus workshop for 3 weeks. Meanwhile, the participants in the control group were exposed to the traditional mathematics teaching about 3D geometry.

\section{Working Group}

30 pre-service elementary mathematics teachers of the last grade from a state university in Turkey participated voluntarily to the study. Randomly, they were divided into two groups. Pre-service mathematics teachers were chosen as the working group because of the importance of drawing perfectly 3D shapes in the mathematics instruction.

\section{Data Collection Tool}

The participant pre-service teachers filled in a test composed of 8 questions which requires the drawings of shapes in $3 \mathrm{D}$ as pre-test and post-test. The questionnaire is prepared by researchers under the supervision of 3 experts in mathematics education.

\section{Procedure}

A pre-test and post-test workshop was organized for the candidates to teach the Cabri3D program. Before the workshop, teachers were asked to draw a blank under the questions.

Within the scope of the Cabri3D Workshop, firstly the menus in the program are introduced and it is mentioned how to clean the screen. Then we can use the right button, right line drawing on the plane, the use of shift key to determine the point in space, two vector drawing on the plane, multiplication of two vectors, straight vertical plane drawing, xyz box drawing using two planes, quadrilateral and so on.

In the prepared test, there are questions about the appearance of shapes from different directions. For this reason, the workshop for the development of the drawing skills in this area also includes drawing, cube drawing, different views of different cubes, creating axes for reflection and rotation, determining planes, finding reflections of any prism, rotating a triangle about 90 degrees around an axis, rotation of a square pyramid about an axis (rotation around an axis, select point smoothly), rotation of a square pyramid by 90 degrees around an axis, rotation of a square pyramid around a circumference by a circle (circle should be around the edge, training was given and applications were made on turning and tracing.

In addition, pyramid drawings, prisms and pyramids were also included in the training application, and eventually the workshop was supported with animation demonstrations.

After the Cabri3D Workshop, the same test was applied to the teacher candidates as a post test. 


\section{Analysis of Data}

For the quantitative part of the study, Mann Whitney $U$ test is used to analyze; because in each group there are less than thirty participants (Cohen, Manion \& Morrison, 2000). In the pre-test and post-test, the correct answers are scored as two points, partial correct answers as one point and wrong answers as zero point.

For the qualitative part, descriptive analysis method has been determined as the basis for the analysis of the data obtained within the scope of the study. Each of the prospective teachers examined the pre-test and post-test in detail, and the drawings they made were evaluated as correct, partially correct, incorrect and empty and tabulated. The questions are divided into three dimensions from two dimensions and three dimensionality from three dimensions. Qualitative data have been added to these quantitative results. During the drawings, the most challenging parts of the prospective teachers and the other drawings reached are directly given.

\section{Findings}

\subsection{Quantitative Analysis}

In order to determine the effect of computer assisted instruction on students' skill of drawing 3D shapes, quantitative analysis is executed. The findings are as below.

Table1. Pre Test Results of Participants

\begin{tabular}{cccc}
\hline & $\begin{array}{c}\text { No of } \\
\text { Part. }\end{array}$ & Mean & Std. Dev. \\
\hline All & 30 & 27,36 & 3,354 \\
Experiment & 15 & 28,67 & 3,251 \\
Control & 15 & 26,57 & 3,657 \\
\hline
\end{tabular}

Table 2. Results of Mann Whitney U test according to pre-test

\begin{tabular}{ccccc}
\hline & $\begin{array}{c}\text { No of } \\
\text { Part. }\end{array}$ & $\mathbf{U}$ & $\mathbf{z}$ & Sig. \\
\hline Experiment & 15 & 103,5 & 1,75 & $\mathrm{p}>0.05$ \\
Control & 15 & & & \\
\hline
\end{tabular}

Results show that there is no statistically significant difference between experiment and control group. These two groups can be considered as identical.

Table 3. Post Test Results of Participants

\begin{tabular}{cccc}
\hline & $\begin{array}{c}\text { No of } \\
\text { Part. }\end{array}$ & Mean & Std. Dev. \\
\hline All & 30 & 23,5 & 3,354 \\
Experiment & 15 & 35,72 & 3,251 \\
Control & 15 & 23,57 & 3,657 \\
\hline
\end{tabular}

Table 4. Results of Mann Whitney U test according to post-test

\begin{tabular}{ccccc}
\hline & $\begin{array}{c}\text { No of } \\
\text { Part. }\end{array}$ & $\mathbf{U}$ & $\mathbf{z}$ & Sig. \\
\hline Experiment & 15 & 124,3 & 2,308 & $\mathrm{p}<0.05$ \\
Control & 15 & & & \\
\hline
\end{tabular}

Results show that the difference between experiment and control group is statistically significant. That difference is in favor of experimental group because their mean score is higher than one of the control group. Therefore it may be concluded that the computer assisted instruction is effective on students' drawing skill.

\subsection{Qualitative Analysis}

In order to determine deeply how computer assisted instruction is effective on students' skill of drawing 3D shapes, qualitative analysis is done. Each question in pre and post test is analyzed and finding are as below. 
Table 5. Pre-test results of each participant in the experimental group

\begin{tabular}{cccccc}
\hline Q. No. & $\begin{array}{c}\text { Transitions between } \\
\text { dimensions }\end{array}$ & True & Partially True & Wrong & Unanswered \\
\hline 1 & 2D-3D & 14 & 0 & 4 & 0 \\
2 & 2D-3D & 7 & 4 & 0 & 5 \\
3 & 3D-3D & 9 & 1 & 8 & 1 \\
4 & 2D-3D & 3 & 6 & 3 & 3 \\
5 & 3D-3D & 3 & 1 & 2 & 0 \\
6 & 2D-3D & 12 & 4 & 3 & 0 \\
7 & 3D-3D & 8 & 1 & 5 & 0 \\
8 & 3D-3D & 9 & 0 & 5 \\
\hline
\end{tabular}

Table 6. Post-test results of each participant in the experimental group

\begin{tabular}{cccccc}
\hline Q. No. & Transitions Between & \multicolumn{3}{c}{ Number of participants } \\
dimensions & True & Partially True & Wrong & Unanswered \\
\hline 1 & 2D-3D & 14 & 0 & 3 & 0 \\
2 & 2D-3D & 10 & 2 & 4 & 0 \\
3 & 3D-3D & 10 & 1 & 4 & 0 \\
4 & 2D-3D & 9 & 2 & 4 & 0 \\
5 & 3D-3D & 6 & 5 & 0 & 0 \\
6 & 2D-3D & 14 & 1 & 0 & 0 \\
7 & 3D-3D & 15 & 0 & 3 & 0 \\
8 & 3D-3D & 11 & 1 & 0 \\
\hline
\end{tabular}

As the findings in Table 5 and Table 6 are compared, it can be seen that in all questions, number of participants that give correct answer is increased. The following graphic show the change in number of participants that give correct answers in pre- and post-test.

Graph 1. The change in correct answers

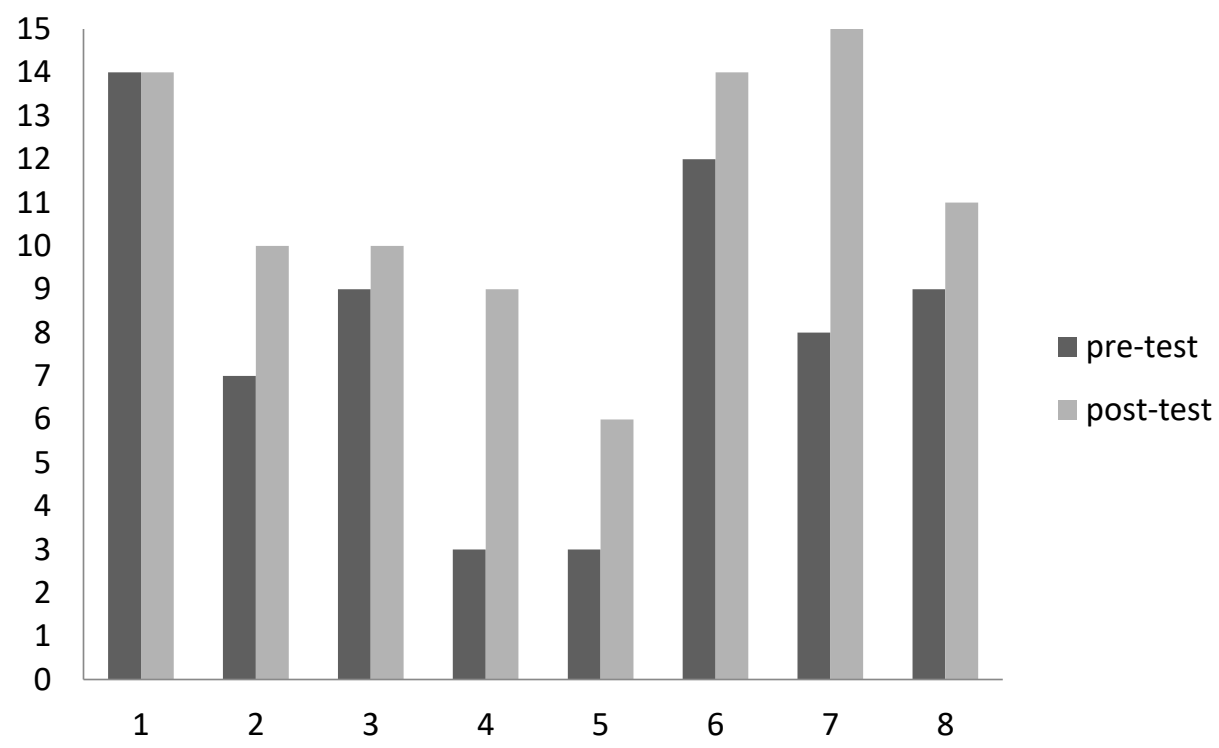

The most significant changes are occurred in question 4 and 7. In the pre-test only 8 participants give correct answer but in contrast in the post-test all participants correctly answer the question 7 (see figure1 and figure2). 


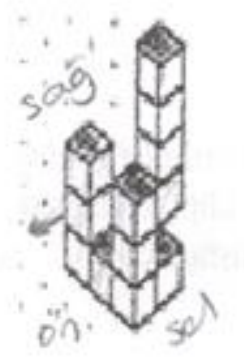

7. Yandaki resimde bir binanın ön soldan görüntüsü verilmiştir. Aynı binanin ön sağdan görünüşünü çiziniz.

Figure1. Example of one participant that give wrong answer to question 7 in the pre-test (Question: Draw the front-right view of the shape which is given from front-left view)

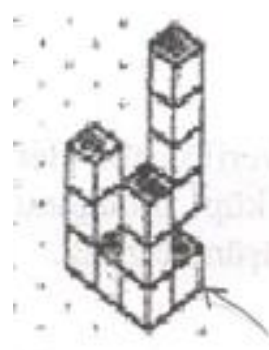

7. Yandaki resimde bir binanın ön soldan görüntüsũ verilmiștir. Aynı binanın ön sağdan görünüşünü çiziniz.
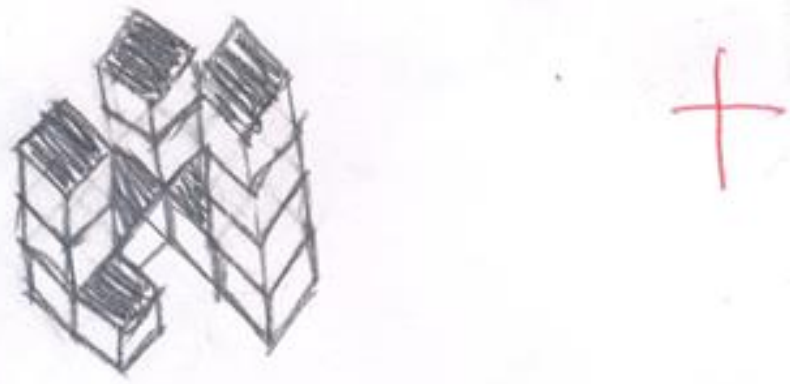

Figure2. Example of same participant that give correct answer to question 7 in the post-test.

The following graphics show respective the change in number of participants that give partial correct and wrong answers in pre- and post-test. 
Graph 2. The change in partial correct answers

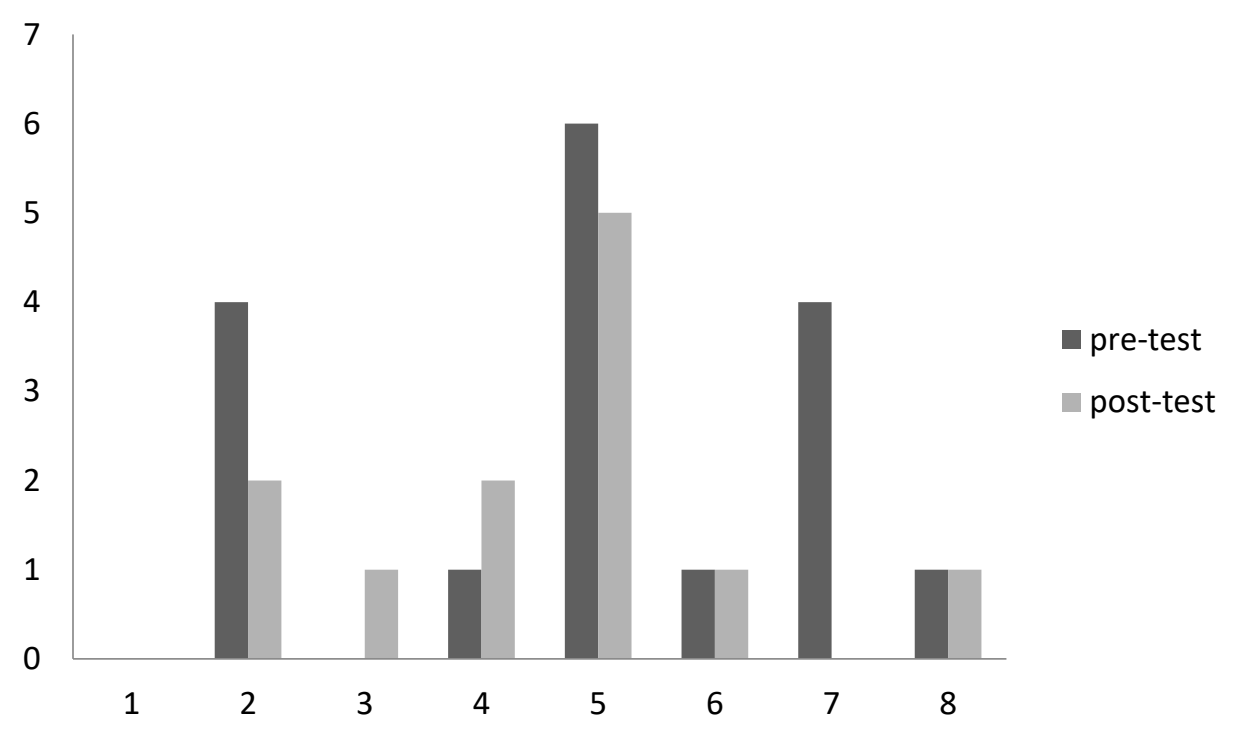

Graph 3. The change in wrong answers

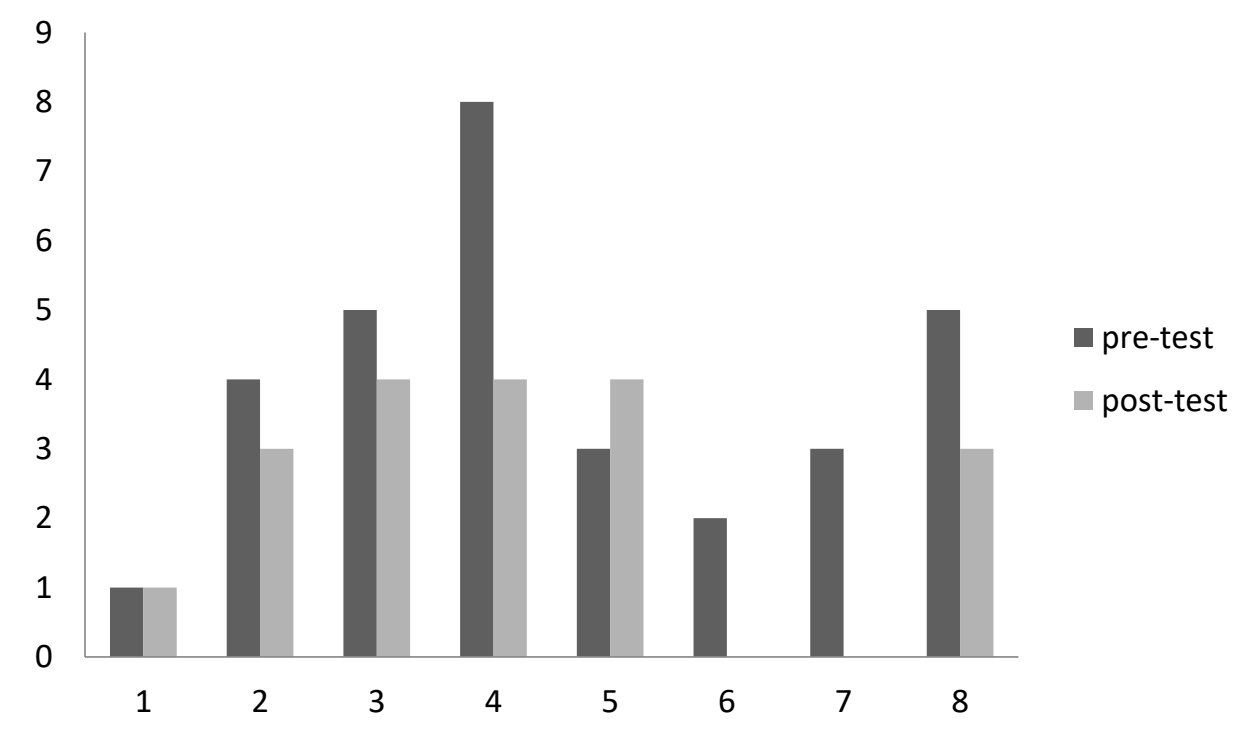

The most significant changes are occurred in question 6 and 7. In the pre-test there are at least 2 participants give wrong answer but in contrast in the post-test none of the participants wrongly answer the questions. An example for the question 6 is given as follow (see figure 3 and figure 4).
6. Bir dik acgenin dik kenarlarıdan birinin etrafinda $360^{\circ}$ dobdoralmesiyle olusan pelki çiziniz.

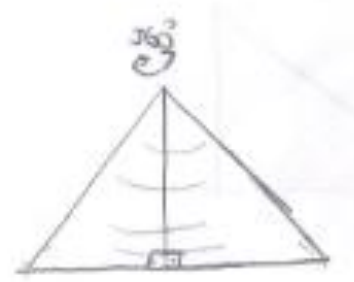


Figure3. Example of one participant that give wrong answer to question 6 in the pre-test (Question: Draw the shape obtained if a right triangle is rotated $360^{\circ}$ with respect to one of its right sides)

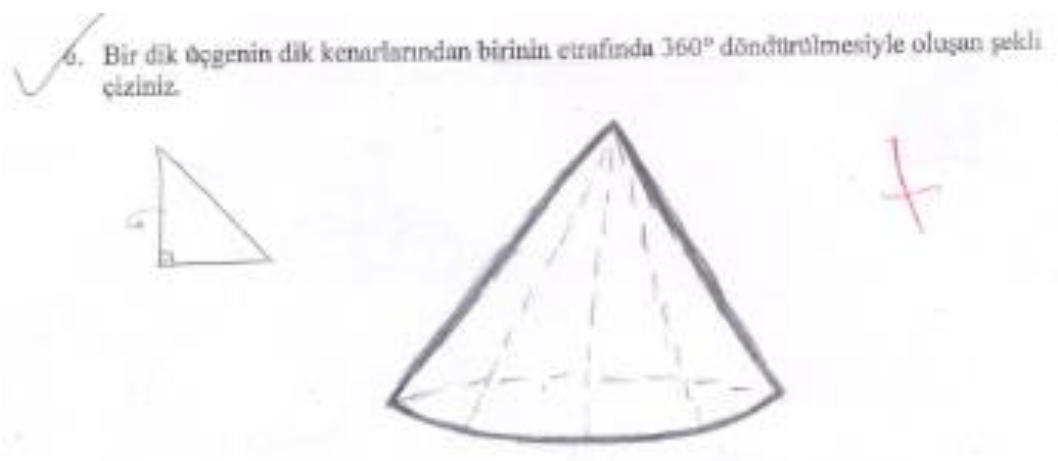

Figure 4. Example of same participant that give correct answer to question 6 in the post-test

\section{Results and Implications}

In this research, the effect of dynamic geometry software on the drawing skill of three dimensional shapes of elementary school mathematics teacher candidates is examined. Findings and interpretations obtained for this purpose are given above.

At the beginning of the study, preliminary application of the success test from the 8 questions about the 3D view of the shapes given to the participants in the experimental and control groups was given. The data of these tests determined the pre-application scores of the students. When the test results were examined, no significant difference was found between the two groups. In other words, the students in the experimental and control groups are considered to be identical before implementation.

After the achievement test was applied as a pre-test, the control group was instructed with the lecture method in the light of the textbook of the Ministry of Education, and the success test applied as a pre-test was applied again as a post-test. The pre-test average for the test group of the experiment group was 28.67 while the final test average was increased to 35.72 and there was a statistically significant difference. The pre-test average of the control group's success test was 26.57, while the final test average was 23.57 , which is statistically significant. In addition, analysis of the post test scores of the achievement test of the experimental and control groups showed a statistically significant increase in the achievement of the students. After the application, the achievement score averages of the students in the experimental group were found to be higher than the students in the control group statistically significantly. This suggests that the computer-aided teaching approach in the selected subject area is more effective in influencing the achievement of the students than the traditional teaching approach. These results are in line with the findings of Şataf (2009) and Gülseçen, Reis, Kabaca \& Kartal (2010) which study the effect of computer assisted instruction on student achievement.

Under the assumption that the success of the students in the experiment group is higher and that there is a meaningful difference in favor of the experimental group in our research, it is thought that the students are interested in technology and Cabri 3D program itself. With a computer-aided learning environment that meets the interests and needs, and a simple and intuitive interface and a dynamic 3D cabriolet, the learning environment appeals to students more. This situation coincides with the findings of Chrysanthou (2008).

With the aid of the Cabri 3D program, the students are able to visualize the three-dimensional shapes in different directions and to answer questions. When the literature is examined, it has been seen that in the studies of spatial visualization in students, computer applications are applied from primary education to university. Olkun (2003) showed that spatial skills of students can be developed with examples of activities designed by elementary school students to improve their spatial skills through engineering drawing approaches. The aim of this project is to develop students' visual thinking skills with dynamic geometry software, which is also aimed at the work carried out by Christou (2007) under the name of DALEST project. Gutierrez (1992), based on the Van Hiele thinking model to understand the three dimensional geometry learning process, emphasized that the application steps of the three-dimensional geometry should include the use of real concrete models, the use of three-dimensional images given on the computer screen, and the plane depictions on paper. Keller, Wasburn-Moses \& Hart (2002) investigate the effectiveness of educational materials based on small-scale applications of isometric drawings, which are thought to help students develop their spatial vision skills, and investigate the effectiveness of educational materials made of these online sources. As a result, educational materials based on small- dimensional representations have improved their spatial vision skills by improving their ability to combine isometric drawings. 
Participants' 3D-3D transitional results increased because the workshop in the research was aimed at improving participants' ability to draw or identifying their ability to draw 3D, as well as improving their drawing skills. In order for the geometric figures to be shown closest to the truth, it is necessary for the teacher candidates to have a high level of drawing skills or appropriate studies should be done to develop them.

Students begin with a single examination in their undergraduate studies, which does not measure their other abilities or their spatial abilities. Although the subject of space geometry is mostly secondary education, there are many shortcomings when students begin their undergraduate studies. Since space geometry involves more high-level abstract concepts and is a much more favorable area for the development of the spatial skills of the students, it is necessary to increase the teaching of this discipline.

\section{References}

Accascina, G., \& Rogora, E. (2006). Using Cabri 3D diagrams for teaching geometry, achievement, spatial visualization and affective factors. American Educational Research Journal, 14, 51-77.

Baki, A. (2008). Mathematics education from theory to practice. Ankara: Harf Eğitim.

Baki, A., \& Güven, B. (2007). The impact of dynamic geometry software Cabri 3D on teacher candidates' spatial abilities. The Proceedings of 7th International Educational Technology Conference, 3-5 May 2007, Near East University -North Cyprus 116-120.

Baki, A., Kösa, T., \& Karakuş, F. (2008). The use of 3D dynamic geometry software in teaching space geometry: Teacher views. A. Kuzu (Ed.), 8th International Educational Technology Conference (s.82-86). Eskişehir, Türkiye: Nobel Press

Battista, M. T. (1990). Spatial visualization and gender differences in high school geometry. Journal for Research in Mathematics Education, 21, 47-60. https://doi.org/10.2307/749456

Ben-Chaim, D., Lappan, G., \& Houang, R. T. (1988). The effect of instruction on spatial visualization skills of middle school boys and girls. American Educational Research Journal, 25(1), 51-71. https://doi.org/10.3102/00028312025001051

Christou, C. (2007). Developing student spatial ability with 3D applications. Submitted to 5th Conference of the European Society for Research in Mathematics Education. Larnaca, Cyprus

Chrysanthou, I. (2008). The use of ICT in primary mathematics in Cyprus: the case of GeoGebra. Unpublished Doctoral Thesis. London: Universitat of Cambridge.

Cohen, L., Manion, L., \& Morrison, K. (2007). Research methods in education. London: Routledge

Dursun, Ö. (2010). The relationships among the preservice teacherse spatial visualization ability, geometry self-efficacy, and spatial anxiety. Unpublished Master Thesis, Middle East Technology University, Ankara.

Grande, J. D. (1990). Spatial sense. Arithmetic Teacher, 15, 14-20.

Gülseçen, S., Reis, Z. A., Kabaca, T., \& Kartal, E. (2010). Reflections on the First Eurasia Meeting of GeoGebra: experiences met on where continents meet. Future, 10, 14.

Gutiérrez, Á. (1992). Exploring the links between Van Hiele Levels and 3-dimensional geometry. Structural Topology 18.

Hoover, W. A. (1996). Constructivism and Geometry. Retrieved on 4.4.2018 from http://www.sedl.org/scimath/compass/v01n03/3.html

Karaman, T. (2000). The relationship between gender, spatial visualization, spatial orientation, flexibility of closure abilities and the performances related to plane geometry subject of the sixth grade students. Unpublished Master Thesis, Bogazici University, İstanbul.

Keller, B., Wasburn-Moses, J., \& Hart, E. (2002). Improving students' spatial visualization skills and teachers' pedagogical content knowledge by using on-line curriculum-embedded applets. National Council of Teachers of Mathematics Illuminations Project.

Kösa, T. (2010). Investigation of the feasibility of the worksheets developed for the vertical projection unit. Journal of New world Sciences Academy, 5(3), 820-838.

Kösa, T. (2011). Examination of spatial skills of secondary school students. Unpublished Doctoral Thesis, Karadeniz Technical University, Trabzon.

NCTM, (2000). Principles and standards for school mathematics. Reston, VA: National Council of Teachers of 
Mathematics.

Olkun, S. (2003). Making connections: Improving spatial abilities with engineering drawing activities. International Journal of Mathematics Teaching and Learning, 3(1), 1-10. https://doi.org/10.1501/0003624

Şataf, H. A. (2009). Transformational Geometry of Primary School 8th Grade Mathematics Instruction and Its Success in the Field of Triangle Lower Learning and Its Impact. Unpublished Master Thesis, Sakarya University, Sakarya.

Skordoulis, C., Vitsas, T., Dafermos, V., \& Koleza, E. (2009). The system of coordinates as an obstacle in understanding the concept of dimension. International Journal of Science and Mathematics Education, 7(2), 253-272. https://doi.org/10.1007/s10763-008-9130-2

Turgut, M. (2010). The effect of technology-assisted linear algebra teaching on spatial skills of elementary mathematics teacher candidates. Unpulished Doctoral Thesis, Dokuz Eylul University, İzmir.

Unal, H., Jakubowski, E., \& Corey, D. (2009). Differences in learning geometry among high and low spatial ability pre-service mathematics teachers. International Journal of Mathematical Education in Science and Technology, 40(8), 997-1012. https://doi.org/10.1080/00207390902912852

Ural, A. (2011). Dimension criteria for mathematics teacher candidates. Pamukkale Üniversitesi Eğitim Fakültesi Dergisi, 30(30), 13-25.

Uygan, C. (2011). The impact of Google Sketchup and concrete model supported applications in teaching solid objects to the spatial skills of elementary mathematics teacher candidates. Unpublished master thesis, Eskişehir Osmangazi University, Eskişehir.

Vitsas, T., \& Koleza, E. (2000). Student's misconceptions on the concept of dimension. In Proceedings of the 2nd Mediterranean Conference on Mathematics Education (pp. 108-119)

\section{Copyrights}

Copyright for this article is retained by the author(s), with first publication rights granted to the journal.

This is an open-access article distributed under the terms and conditions of the Creative Commons Attribution license which permits unrestricted use, distribution, and reproduction in any medium, provided the original work is properly cited. 